\title{
Assessment towards Innovation: Examining Feedback Methods in the Design Studio
}

\author{
By Lisa Phillips*
}

In higher education creative disciplines are often acknowledged as lacking formal student assessment methods which illustrate both depth and consistency. Much to the frustration of students, the markers of successful design projects are frequently defined by seemingly subjective nuances, providing obstacles to those looking for tangible ways to increase their skill sets. At the core of a design education, the studio must lead the way in providing clear feedback, essential to the development of the varied facets of design.

In alignment with student needs for reliable communication, the academic environment is progressively becoming more moderated. Often, instructors are required to provide quantifiable measures of assessment to governing and accrediting bodies. Without exams or papers, studio projects are likely to use rubrics, many of which have been adapted from more objective disciplines.

This paper seeks to formulate strategies for assessment in design education that can assist students in achieving course outcomes while providing feedback in a clear and balanced manner. How can assessment act as a means to continually move student designs not just toward success, but also innovation? How does one effectively evaluate creativity, curiosity and even risk taking?

Following interior design students over the course of a semester, this case study documents the success rate of various forms of assessment used to deliver feedback. Methods included analytic scoring scales, primary trait analyses and collaboratively developed rubrics. Using focus groups, surveys and written prompts, students reflected on how beneficial each method was to improving their understanding of excellence in design. The instructor also reflected on how useful each was in assessing the achievement of teaching methods and course learning outcomes.

\section{Can Design be taught?}

In the world of design there are students who have the natural ability to effortlessly conceive ideas and visualize an accurate end result. These fortunate individuals understand innately how to approach a studio problem, organize space effectively and communicate their intentions clearly to an audience.

*Assistant Professor, Interior Design,Philadelphia University, Philadelphia, USA 
Others have the desire and passion, but not necessarily the intuition to be immediately successful in these complex academic environments. Is it possible to teach this second set of students to improve, and even to master, the design disciplines? There has been much debate over the centuries as to whether creativity can be taught. Correspondingly, can design be taught?

It is widely accepted that good design relies on many principles that are universal despite race, nationality or religion. Balance, rhythm, proportion, and harmony are just some of the known elements in this category. These principles are indeed taught in any number of foundation studios and classrooms around the world and are reasonably easy to recognize.

In addition to considering these principles, there are other factors that can be used when determining the success of a student of design. These additional criteria can be more elusive, however, as design is a discipline where ingenuity itself is celebrated. In these fields 'learners are encouraged to progressively extend the arena of possibilities within which they operate, not to seek enduring solutions or answers but to open up unfamiliar territory and new ideas.' (Danvers, 2003) Rarely are rules provided for students to follow, rather the breaking of rules and traditions is rewarded.

It is not surprising that students of design often become frustrated with their experiences in higher education. These majors, by their intrinsic nature, are more subjective than objective, more qualitative than quantitative. It is difficult to succeed where definitive answers rarely exist and where effort alone does not guarantee a positive end result.

In these demanding fields students need much guidance from their instructors to move forward, particularly in the way of authentic feedback concerning their process and product.

It has been shown that 'academic feedback is more strongly and consistently related to achievement than any other teaching behavior. This relationship is consistent regardless of grade, socioeconomic status, race, or school setting. When feedback and corrective procedures are used, most students can attain the same level of achievement as the top 20\% of students.' (Bellon, Bellon \& Blank, 1992).

This paper focuses specifically on the value of feedback as a means to increase student learning in design studios. It critically examines both informal feedback and formalized assessments currently in use in architecture and interior design curriculum and discusses student expectations and preferences in feedback methodologies.

\section{A History of Ineffectual Feedback}

Education practices in the building arts are often as challenging for instructors as they are for students. Pedagogy in these fields is built on 
tradition, with most universities worldwide using a similar technique for teaching design studio, one that has survived many decades of use.

The Ecoles des Beaux Arts teaching philosophy was spread internationally in the early part of the 19th century. The foundation of the Beaux Arts structure was the studio based learning model where a project problem was assigned to students and developed while working under a master of design. The Beaux Arts teaching system relied on an individual lesson, essentially a modern desk critique, and completed projects were evaluated by a jury of instructors and professionals.

The desk critique of today, is still an informal process with the power to teach and also to provide purposeful feedback to students. When functioning at a high level, with an experienced instructor, students, in fact, prefer desk critiques as their primary method of feedback in the studio setting.

A design jury, by contrast, is the more formal Beaux Arts inspired review that often occurs during key points in a project schedule, as well as at the final. This process is not that dissimilar to the legal proceeding by the same name, where a student is essentially put on "trial" and judged by a body of experts who decide whether the individual is guilty of crimes of style, function and aesthetics.

Although seemingly, a controlled environment to provide feedback from multiple professional sources, these critiques often act as soapboxes for the jurors to showcase their egos, rather than contribute valid strategies concerning how the student might improve.

A student recently shared her frustration: 'Juries give a lot of feedback but often it conflicts so sometimes it's confusing. What should I have done differently? Who should I listen to when everyone is saying something different? It's not clear.'

Unfortunately, the conversations from desk critiques and design juries are often the only source of feedback provided to students throughout the course of the semester. The quality is only as good as the experience of the teacher and/or the jurors. Although many teachers of design may be excellent practitioners they have rarely been exposed to pedagogical strategies for higher education, let alone specifically for design.

If an instructor is not making consistent, focused assessment a priority, students are often unsure how to improve their work. In these cases, the grade at the end of the course comes without any precursor, sometimes corresponding with expectations but often as a complete surprise.

One student explains: 'Sometimes I got good feedback during the desk crits and then when I received the grade at the end of the semester I was shocked. I was upset because it was the end of the term and I couldn't do anything to change it. It's not so much about always hearing what I've done right, it's also probably more important what I did wrong. I want to know why.'

This comment speaks to a common justification instructors give for not providing feedback when in one-on-one scenarios: they don't like to create 
confrontational situations with their students by injecting negative comments. Instead they only provide positive remarks or they avoid them at all.

A balance must be struck between positive and negative feedback. Neither alone helps students to improve. As long as it is constructive, students prefer hearing honest commentary. Without it, these same students are left to look to the work of their classmates who have been deemed successful and try to emulate their style, rather than making changes based on individualized observations on their own project.

How have we allowed such a history of inconsistent feedback in our design studios? Clearly, the justification of tradition alone will not suffice if we, as educators, wish to maintain the highest degree of education available to our students.

\section{Defining Excellent Design Behaviors}

If students will be evaluated, they need to know the criteria they will be tested by. These are different for each teacher, course and even for each project. Student learning goals can be created by specifically examining the targets for an activity (or course) and defining observable expectations for that task.

Because design studios are primarily qualitative, many inexperienced instructors are easily intimidated creating learning goals. In fact, when initially asked how they determine an "A" student many teachers often say "I know one when I see them" or "It comes with experience." Development of goals becomes easier when these same instructors are pressed to consider explicit questions, such as:

- How does one define the specific behaviors of an exceptional student in your field?

- What sets them apart and makes them stand out from their fellow classmates?

- What is different about their process, their development and their end product?

In an effort to increase the validity of student learning goals I have recently collected data from other design instructors posing these questions. Pilot work conducting interviews with my colleagues has already revealed patterns in the answers that can be of benefit in assisting instructors to develop student learning goals for their studio courses.

As a result of this study, excellent students of design should be able to demonstrate that they are:

- comfortable taking chances and risks

- independent workers who are self motivated

- a refiner and self editor 
- passionate about everything they do

- curious

- capable of creating spaces that address human behaviors

- able to look at a problem in many different ways and ask "what if?"

- capable of pushing themselves beyond the ordinary and what they are already good at

- critical of their own work

- not afraid to let go of their first idea

- able to carry an idea through two dimensionally and three dimensionally

- competent applying the principles of good design (hierarchy, balance, etc.)

- able to create projects that are both aesthetically pleasing and functional

\section{Methods of Feedback}

'Measurement is the first step that leads to control and eventually to improvement. If you can't measure something, you can't understand it. If you can't understand it, you can't control it. If you can't control it, you can 't improve it'. - H. James Harrington

Once student learning goals have been defined, educators need tools to measure them effectively. The two main types of feedback are formative and summative assessments. Formative occurs during the course of a project. It acts as a type of 'weigh in' for students so it is rarely graded. 'It is usually descriptive, specific and it is directed toward behaviors that students can do something about'. (Bergquist and Phillips, 1975) Formative feedback can easily be accomplished verbally during desk critiques or with more formalized written feedback.

'Summative assessment, by contrast, is concerned with gathering information about learning after the learning has occurred, usually for the purpose of assigning a grade'. (Anderson \& Krathwohl, 2001). It generally occurs at key points in the semester and at the end of projects. The feedback can still be verbal but in design studio it is often provided as written comments or in a standardized format.

It has been shown that only through a continuous cycle of both types of feedback that excellence results 'Students must have routine access to the criteria and standards for the task they need to master (i.e. learning goals); they must have feedback in their attempts to master those tasks; and they must have opportunities to use the feedback to revise work and resubmit it for evaluation against the standard. Excellence is attained by such cycles of model-practiceperform-feedback-perform.' (Wiggens, 1998) 


\section{A Student Survey on Feedback}

Regardless of how adept an instructor is at creating learning goals and assessment methods, it is always prudent to have students weigh in with their preferences as well. How much feedback do they desire and what type do they deem the most helpful?

To this end, a survey was conducted in spring 2013 polling approximately 50 architecture and interior design students in the $3^{\text {rd }}$ year of their undergraduate education (or higher), focusing on the design studio setting specifically.

An overwhelming $100 \%$ of students surveyed said that they would rather receive feedback (of any kind) in addition to a letter grade, than to receive just a letter grade alone. Despite this statistic, 35\% of students noted that they often received no formative feedback on their work.

Students were also asked which areas of feedback provided the most value in a design studio. (Figure 1) The clear standouts were design, process and presentation, with technical skills also presenting a sizable number of responses. Only 4\% said completion, which is the most used criteria many new faculty members use. Unsure of how to provide feedback, they rely on a simple checklist of final requirements. Students already know what they didn't finish, however. It is information relevant to their growth as a designer that they covet.

Figure 1. Results of Student Survey Question on Most Valued Area of Feedback

In which of the following areas do you most value feedback?

Students were asked to select 3 of the selections in the survey. The numbers below indicate the percentage of students who selected that answer in the survey.

$94 \%$ Design

$66 \%$ Process

4\% Completion

72\% Presentation

36\% Technical skills

$11 \%$ Work Ethic

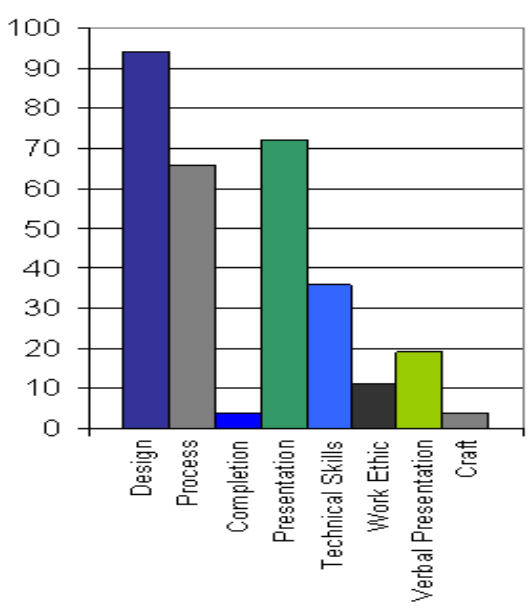

$19 \%$ Verbal Presentation

4\% Craft

0\% Other (define below) 
Another insight gained from the survey was provided from a question that asked which type of format the students felt was most helpful in their development. Students preferred a detailed rubric (i.e.: a written guide with specific criteria for evaluating a project) as long as it had some additional written comments. In second and third place was verbal feedback, either in the form of a private, personal interview with their instructor or in the form of a desk critique.

\section{A Case Study}

In addition to the survey above, a small case study was conducted to document the success rate of various forms of feedback in a third year interior design studio. Over the course of a semester eight students were interviewed, both at the beginning of the term and at the end. Throughout the semester, various methods of feedback were used.

For formative assessments verbal conversations at desk critiques and private conversations were utilized, in addition to holistic, written comments during informal group critiques. For summative feedback at juries, more formal rubrics in the form of analytic scoring scales and primary trait analyses were used.

Regardless of the method, the learning goals were reviewed with students and they were able to view, in advance, the method of evaluation - ideally right when the project was introduced. Knowing how they would be graded and understanding that specific behaviors could impact their score allowed the students to have a clearer understanding of expectations.

Using focus groups, surveys and written prompts, students expressed that they preferred feedback that was highly personalized and specifically spoke to their individual strengths and weaknesses in design. In fact, holistic, written feedback (Figure 2) was favored by the majority of students over most rubrics. This information was consistent with the college survey conducted.

Figure 2. Examples of Holistic Feedback

\section{Holistic Feedback}

(spoken or written)

"You seem to work fairly consistently but the design radically change often and without apparent reason. Try to find a design you can work with through the details and bring it through refinement."

"There are many creative elements in the design but it lacks cohesion. It seems as though it is inspired by several different existing projects rather than by your unique vision of the concept."

"Your ideas have great potential but you fail to apply yourself in pushing your idea to be all that it can be. Try to be more exploratory in your process, researching your concept and working through multiple iterations of the design. 
Although preferred, this method constitutes a lengthy time investment by the instructor. It also relies on the skill of the teacher to focus their feedback on criteria the students find helpful. The possibility of inconsistency from student to student is high with this method.

Students also found individual meetings to discuss progress to be useful. It should be noted that these were most likely successful because the teacher used a clear list of criteria to discuss with each student. Again, consistency is only as good as the instructor's understanding of assessment.

The technique that was noted as most reliable by both students and the instructor was a complex primary trait analysis. This extensive rubric featured many criteria that provided explanations of successful behaviors and project indicators that easily allowed the instructor to evaluate course learning goals. (Figure 3)

Figure 3. Example of Student Learning Goals in a Primary Trait Analysis

\begin{tabular}{|c|c|c|c|c|}
\hline & Exemplary & Accomplished & Developing & Formative \\
\hline $\begin{array}{c}\text { Risk } \\
\text { Taking }\end{array}$ & $\begin{array}{l}\text { Student often } \\
\text { worked as an } \\
\text { independent } \\
\text { worker and the } \\
\text { final project } \\
\text { showed the } \\
\text { benefits of their } \\
\text { self-motivation }\end{array}$ & $\begin{array}{c}\text { Student } \\
\text { worked } \\
\text { independently } \\
\text { often }\end{array}$ & $\begin{array}{l}\text { Student } \\
\text { occasionally } \\
\text { relied on } \\
\text { instructor } \\
\text { and/or others to } \\
\text { move the design } \\
\text { forward }\end{array}$ & $\begin{array}{l}\text { Student often } \\
\text { relied on } \\
\text { instructor } \\
\text { and/or others to } \\
\text { move the } \\
\text { design forward }\end{array}$ \\
\hline Curiosity & $\begin{array}{l}\text { Student } \\
\text { thoroughly } \\
\text { explored concept, } \\
\text { precedents and } \\
\text { researched a } \\
\text { considerable } \\
\text { number of options } \\
\text { as they designed }\end{array}$ & $\begin{array}{l}\text { Student } \\
\text { reasonably } \\
\text { explored } \\
\text { concept, } \\
\text { precedents and } \\
\text { researches } \\
\text { reasonable } \\
\text { options as they } \\
\text { design }\end{array}$ & $\begin{array}{l}\text { Student shows } \\
\text { only some } \\
\text { evidence of } \\
\text { research of } \\
\text { design. More } \\
\text { thorough } \\
\text { exploration } \\
\text { could have } \\
\text { greatly } \\
\text { improved the } \\
\text { project }\end{array}$ & $\begin{array}{l}\text { Student showed } \\
\text { little or no } \\
\text { evidence of } \\
\text { research or } \\
\text { concept } \\
\text { exploration. }\end{array}$ \\
\hline
\end{tabular}

Slide scale rubrics rated significantly lower with the students, as they did in the college survey. These rated number systems (Figure 4) only seemed to be acceptable if they were accompanied by extensive personal feedback. 
Figure 4. Two Examples of Slide Scale Formats

\section{Poor (1), Developing (2), Average (3), Accomplished (4), Exemplary (5)}

\section{Risk Taking}

(Student works as an independent worker and the final project shows the benefits of their self motivation)

\section{Curiosity}

Student thoroughly explores concept, precedents and researches a considerable number of options as they designed
5

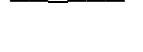

\section{Projects will be rated on a scale of $1-5$ with $1=$ poor, $5=$ excellent}

$\begin{array}{llllll}\text { Risk Taking } & 1 & 2 & 3 & 4 & 5 \\ \text { Curiosity } & 1 & 2 & 3 & 4 & 5\end{array}$

\section{Conclusions}

The surveys and case study revealed several patterns concerning student expectations for feedback that can be valuable to instructors when considering both formative and summative assessment formats.

Expectations for students need to be clear from the beginning of a course and/or project. This occurs by clearly establishing student learning goals and assessment criteria that address these goals specifically.

The more detailed the feedback (and more personal) the more students preferred the methods. Sometimes personal feedback can be difficult to obtain in formal rubrics. It is encouraged to provide honest feedback verbally at desk critiques but it is also appropriate to jot down additional notes on standardized methods of assessment as well.

Students can't get enough feedback. They desire a great quantity but the amount isn't as important as the quality. Consistency is the primary goal with all feedback. Primary trait analyses seem to do the best job of this and they require less individualized comments if written descriptively.

When these observations are taken into account, the mystery of design is unveiled and a clear set of rules are established, rules that teachers can measure and that students can indeed understand, control, and ultimately, improve. It is in this way, that assessment and feedback can undeniably become powerful tools to teach design. 


\section{Bibliography}

Anderson, L.W., \& Krathwohl, D.R. (2001). A Taxonomy for Learning, Teaching and Assessing: A revision of Bloom's Taxonomy of Educational Objectives: Complete edition, New York : Longman.

Bellon, J., Bellon, E, \& Blank, M.(1992). Teaching from a Research Knowledge Base: A Development and Renewal Process. New York: Merrill Publishing Company

Bergquist, W. \& Phillips, S. (1975). Handbook for Faculty Development. Washington: Council for Advancement of Small Colleges. LB2331.B45

Danvers, J. (2003). Towards a Radical Pedagogy: Provisional Notes on Learningand Teaching in Art and Design. Journal of Art and Design Education 22 (1), pg. 50

Wiggins, G. (1998) Educative Assessment: Designing Assessments to Inform and Improve Student Performance. San Francisco: Jossey-Bass Inc.. 